\title{
KOMPARASI KEKERASAN BAJA ST 60 SETELAH MENGALAMI PREHETING DAN PENGELASAN TERHADAP KEKERASAN
}

\author{
${ }^{1)}$ Gumono, ${ }^{2)}$ Bambang Irawan, ${ }^{3)}$ Nila Aulia \\ 1,2,3) Jurusan Teknik Mesin Politeknik Negeri Malang \\ ${ }^{1)}$ gumono@polinema.ac.id, ${ }^{2)}$ bambang.irawan@polinema.ac.id, ${ }^{3)}$ nilaalia@gmail.com \\ (Artikel diterima: Februari 2020, direvisi: April 2020, diterima untuk terbit: Juli 2020)
}

\begin{abstract}
Abstrak - Pengelasan adalah proses penyambungan dua atau lebih logam atau lebih dengan tekanan atau tanpa tekanan, Untuk mendapatkan sifat mekanik yang bak maka saat awal proses pengelasan harus diperhatiak agar tidak terjadi penurunan sifat mekanik. Tujuan penelitian ini untuk mengetahui berapa besar perubahan kekerasan baja st 60 yang mengalami pengelasan dengan arus 100, 110 dan $120 \mathrm{amp}$ dan di preheating dengan suhu 200,300 dan $400^{\circ} \mathrm{C}$. Metoda pembentukan spesimen sesuai standart jis Z 3121 . Data selanjutnya disajikan dalam bentuk grafik untuk dikomparasikan. Hasil saat preheating $400^{\circ} \mathrm{C}$ terhadap $200^{\circ} \mathrm{C}$ di daerah $\mathrm{HAZ}$, sedang di weld metal 10,40HV Yang terjadi saat preheating $400^{\circ} \mathrm{C}$.
\end{abstract}

Kata kunci: Kekerasan, Pengelsan, Weld metal, Ddaerah terpengaruh panas.

\section{Pendahuluan}

Pengelasan adalah cara penyambungan antara 2 (dua) atau lebih logam dengan mencairkan sebagian logam induk dan logam pengisi dengan atau tanpa tekanan dan dengan atau tanpa logam penambah dan menghasilkan sambungan yang kontinyu. Untuk mencairkan logam induk dan pengisi memerlukan energy panas yang tinggi. Pada proses pengelasan SMAW energi panas bersumber dari hasil lompatan ion (katoda dan anoda) listrik yang terjadi pada ujung elektroda dan permukaan material. Pada proses pengelasan SMAW arus pengelasan berperan dalam membentuk tetesan logam saat proses penyambungan berlangsung. Kondisi ini menentukan kekerasan pada sambungan las dan (HAZ).

Pada pengelasan menggunakan SMAW diameter elektroda, besar arus jenis kawat las, komposisi kimia logam induk, tebal logam induk dan posisi pengelasan selain temperature pemanasab awal saat sebelum proses pengelasan berlangsung (preheating) logam induk. Kondisi ini menyebabkan besar arus pengelasan berpengaruh terhadap hasil akhir proses pengelasan. Saat arus terlalu rendah menyebabkan busur listrik sulit menyala dan busur listrik yang terjadi tidak stabil. Kondisi ini akibat energi panas yang diperlukan untuk melelehkan elektroda dan logam induk kurang, sehingga hasil lasan berbentuk rigi-rigi las yang kecil dan tidak rata serta penembusan yang kurang dalam. Bila arus terlalu besar menyebabkan elektroda cepat mencair, sehingga hasil pengelasan permukaannya lebih lebar dan penembusan dalam.

Temperatur preheating sebelum pengelasan awal dilakukan berperan dengan tujuan untuk membuka atau mengembangkan ukuran butiran. Saat ukuran butirannya mengembang maka unsur lain dapat masuk ke dalam antara butiran, sehingga menjadi padat yang berkibat neiknya kekerasan logam. Tujuan penelitian ini untuk mengetahui berapa besar perubahan kekerasan baja st 60 yang mengalami pengelasan dengan arus 100, 110 dan 120 amp dan di preheating dengan suhu 200,300 dan $400^{\circ} \mathrm{C}$

Peneliti terdahulu tentang pengaruh temperatur preheating dan kuat arus pada peneglasan baja ST 60 terhadap kekuatan tarik dan kekerasan dilakukan oleh, Achmad N. dkk. 2015. Pada pengelasan baja st 60 tebal $8 \mathrm{~mm}$ menggunakan elektrode E 7016 menyimpulkan bahwa gerakan elektroda memberikan pengaruh pada hasil kekerasan. Hermawan W. 2014. Pengelasan baja ST 60 menggunakan las gesek menyimpulkan nilai kekerasan pada sambungan tertinggi 243,8 HVN daerah HAZ, logam induk sebesar 231,8 HVN. Ma'ruf. 2017. Pengelasan baja st 60, elektrode jenis E 6013. dan arus pengelasannya 70, 80 dan 90 amp menyimpulkan bahwa kekerasan logam las tertinggi pada arus 90A nilainya $89 \mathrm{HRB}$, untuk $80 \mathrm{~A}$ nilainya $93 \mathrm{HRB}$ dan arus 70A nilainya 92,81HRB

\section{Tinjauan Pustaka}

\section{A. Parameter Pengelasan}

Menurut Wiryosumarto \& Okumura (2008), daerah hasil pengelasan dibedakan menjadi tiga bagian yaitu : daerah logam las, daerah pengaruh panas atau heat affected zone disingkat menjadi HAZ dan logam induk yang tak terpengaruhi panas, Faktor yang mempengaruhi pengelasan SMAW diantaranya besar tegangan, sebab tergantung pada panjang busur listrik untuk ukuran yang baik sebesar setengah diameter elektroda. Besar kecilnya arus saat pengelasan tergantung komposisi dan tebal logam induk, bentuk kampuh, posisi pengelasan, jenis elektroda, dan diameter elektroda. Untuk arus listrik yang rendah dan diameter elektroda yang lebih kecil digunakan untuk pengelasan benda kerja yang kecil, sedang benda kerja yang tipis arusnya lebih rendah. Untuk daerah las yang memiliki kapasitas panas tinggi akan memerlukan arus las yang besar, bahkan perlu pemanasan awal.

kecepatan pengelasan tergantung dari jenis dan diameter elektroda, komposisi kimia dan sambungan. Kecepatan pengelasan sebanding dengan besar arus, di mana saat kecepatan tinggi perlu arus besar. Berbeda dengan gerakan pengelasan di mana makin cepat gerakan pengelasan semakin kecil panas yang ditimbulkan sehingga perubahan bentuk bahan dapat dihindarkan. Untuk mendapatkan hasil pengelasan yang optimum maka perlu mengatur panjang busur, kecepatan pengelasan dan pemakanan elektroda yang konstan sesuai dengan gerakan elektroda. 


\section{B. Elektroda}

Elektroda terdiri bagian inti yang terbuat dari baja yang berfungsi sebagai bahan pembungkus (fluks) dan bahan pengisi (filler). Fluks berfungsi melindungi logam cair dari udara sekitar, menjaga busur listrik agar tetap stabil, sebagai deoksidator, menghasilkan gas pelindung, mengurangi percikan api dan uap pada pengelasan, dan sebagai sumber dari unsur paduan. Kode elektroda sudah distandarkan atau ditetapkan dengan standar AWS (American Welding Society) dan ASTM (American For Testing Material). Menurut AMW elekrode diklasifikasikan berdasarkan huruf $\mathrm{E}$ dan diikuti empat atau lima digit sebagai berikut $\mathrm{E} x \mathrm{xxx}(\mathrm{x})$. Dua digit yang pertama atau tiga digit menunjukan kuat tarik hasil las. Sebagai contoh elektrode E 6013 mempunyai kuat tarik $60.000 \mathrm{psi}$ (42 Kg/mm2 ), digit selanjutnya menujukan posisi pengelasan di mana untuk angka 1 untuk semua posisi pengelasan, angka 2 untuk las datar (horizontal) sedang untuk angka 1 dan angka 3 menunjukan untuk pengelasan datar saja. Digit yang terakhir menunjukan jenis dari campuran kimia dari lapisan elektrode.

Penyulutan elektroda merupakan proses hubung singkat, yang terjadi antara ujung elektroda dengan logam benda kerja yang kemudian secepat mungkin memisahkannya dengan jarak tertentu (biasanya setengah dari diameter elektroda). Busur nyala listrikakan padam saat posisi elektrida dekat dengan benda kerja, kemudian secepat mungkin dijauhkan. Langkah pemadaman busur listrik ini perlu diperhatikan karena akan mempengaruhi kualitas pengelasan (siswanto R. 2012). Saat proses pengelasan berlangsung agar saat melakukan pengelasan dengan las busur nyala listrik didapatkan urutan manik las pada sambungan yang merata, halus, serta menghindari terjadinya takikan dan kubangan terak

\section{Arus Listrik}

Arus listrik yang digunakan untuk pengelasan SMAW adalah arus DC (Direct Current) dan arus AC (Alternating Current).

\section{Keuntungan}

1. Dapat dipakai untuk semua jenis logam dan posisi pengelasan bervariasi.

2. Dapat untuk mengelas dengan ketebalan yang bervariasi sebab diameter elektrodanya bervariasi.

3. Pengaturan arus dan tegangannya mudah.

4. Tidak bising saat digunakan.

5. Tidak sensitif terhadap korosi, oli dan gemuk.

\section{Kerugian}

1. Pengelasan hanya sampai sepanjang elektoda sehingga proses berukutnya perlu penyambungan.

2. Perlu pembersihan terak dan tidak dapat untuk pengelasan bahan baja non - ferrous.

3. Mudah terjadi Oksidasi akibat pelindung logam cair hanya busur las dari fluks.

4. Diameter elektroda tergantung dari tebal pelat dan posisi pengelasan.

5. Elektroda jenis tertentu sebekum digunakan harus disimpan dalan oven,

\section{Panas awal (Pre Heating)}

Pemanasan awal adalah proses memanaskan benda kerja sebelum pengerjaan lanjut. Pada benda kerja yang tebal perlu dilakukan, sebab saat proses pengelasan di daerah HAZ perlu panas tinggi. Pada daerah logam yang mencair perlu panas tinggi, bertambah jarak busur akan menyebabkan panasnya (heat input) berkurang. Pemanasan dan pendinginan yang tidak merata (perubahan termperatur) akan menyebabkan perubahan pada HAZ utamanya pada keuletan, keliatan, tegangan tarik dan sifat Iainnya.

Pemanasan awal logam sebelum pengelasan berdampak pada pengurangan perbedaan temperatur pada daerah pengelasan. Kondisi ini merupakan satu cara untuk mengatasi perubahan-perubahan pada logam yang mengalami proses pengelasan, sebab pemanasan sebelum pengerjaan akan mengurangi perubahan temperatur. Kondisi ini mengakibatkan berkurangnya perubahan bentuk dan tegangan akibat pengaruh panas yang tinggi pada daerah las. Tinggi temperatur pemanasan awal tergantung pada:

1. Komposisi kandungan unsur dan baja sebab komposisi baja akan menentukan kekerasannya. Pada baja karbon yang baru mengalami proses pengelasan dan selanjutnya didinginkan secara cepat, maka dapat berakibat keretakan pada benda kerja, Pemanasan sebelum pengerjaan perlu dengan tujuan untuk memperlambat pendinginan supaya tidak retak pada daerah yang dilas/dipanaskan.

2. Ketebalan benda kerja di mana semakin tebal benda kerja, maka semakin besar pula pengaruh pendinginan dan dengan semakin tebalnya bahan maka semakin lama pemanasan awal yang dipenlukan.

3. Sumber panas yang terjadi pada saat pengelasan dan pemanasan awal pada bahan-bahan baja sangat bervariasi. Untuk mengetahui temperatur pemanasan awal untuk berbagal jenis dan ketebalan pelat berdasarkan katalog pembuat baja tersebut. Pemanasan awal digunakan untuk pengelasan bahan yang mudah retak dan sulit dilakukan proses pengelasan dengan tujuan memperlambat proses pendinginan.

\section{3. METODA DAN BAHAN}

\section{A. Metodologi}

Diagram alir penelitian ini menunjukkan urutan yang dilakukan selama pengerjaan.

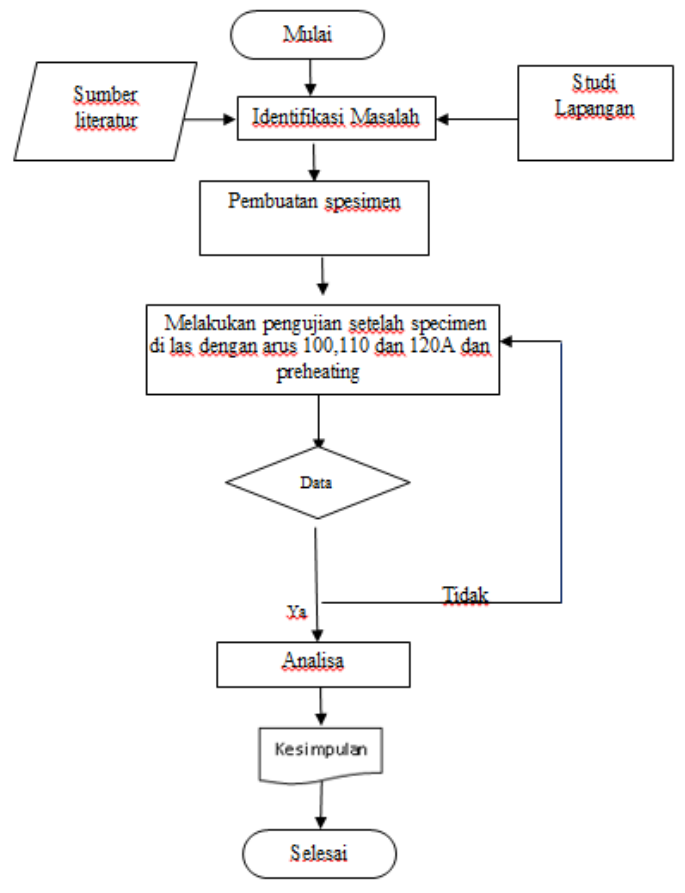

Gambar 1 Diagram alir 


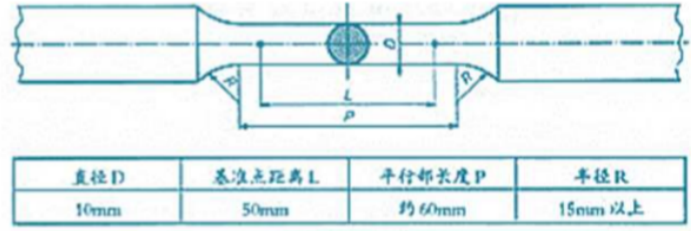

Gambar 2 Standar JIS Z 3121

\section{B. Bahan Uji}

Bahan uji baja ST 60 di mana pelaksanaan pembuatan specimen dan pengujian di workshop dan laboratorium. Bahan plat ST 60 dibentuk spesimen sesuai standar jis $Z$ 3121, selanjutnya spesimen di preheating dan dilakukan pengelasan menggunakan elektroda E7018 variasi arus sebesar 100A, 110A dan 120A. Setelah pengelasan, spesimen didinginkan dengan oli dan dilakukan pengujian kekerasan pada HAZ dan weld metal. Variabel dalam penelitian terdiri dari variabel bebas dan variabel terikat. Variabel bebas adalah kuat arus, temperatur preheating. Variabel terikat adalah nilai kekerasan hasil pengelasan.
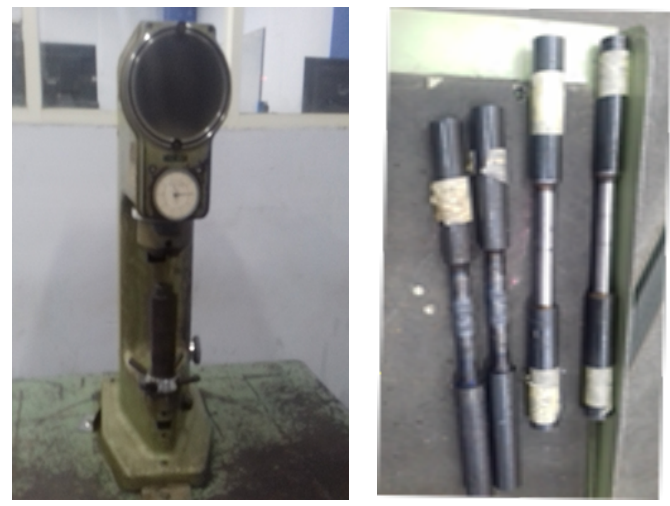

Gambar 3 Spesimen uji

\section{Bahan dan alat}

Bahan terdiri dari

1. Baja st 60.

2. Elektrode E 7018.

3. Kertas gosok

Alat terdiri dari,

1. Mesin las GMAW semi otomatis (kondisi standart) 2. Meja las.

3. Thermo kople K.

4. Dapur listrik induksi

5. Mesin uji kekerasan

6. Gerinda

\section{Hasil dan Pembahasan}

\section{A. Hasil}

Gambar 4 menunjukkan hasil uji kekerasan setelah pengelasan menggunakan elektroda E 7018 dengan arus 100amp. Suhu preheating 200, 300 dan $400^{\circ} \mathrm{C}$, pengujian kekerasan menggunakan metoda vickers. Lokasi pengujian kekerasan pada logam induk, HAZ dan weld metal (logam las), setiap sampel diuji sebanyak lima titik untuk memperoleh nilai kekerasan reratanya, untuk pengelasan dengan arus 100amp saat suhu preheating $200^{\circ} \mathrm{C}$

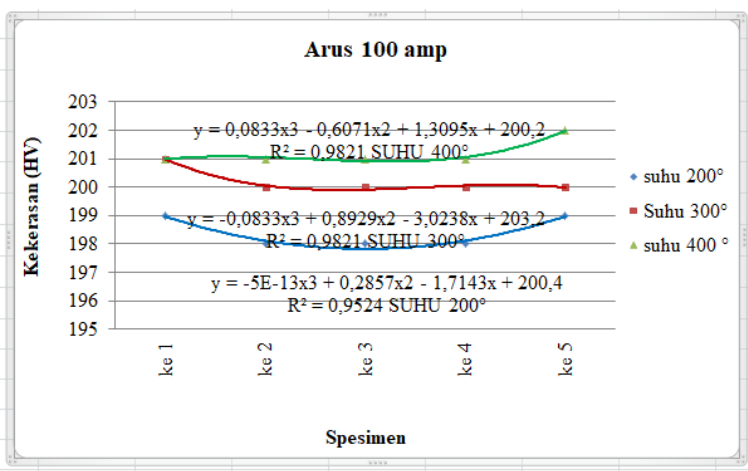

Gambar 4 Perbandingan kekerasan di daerah HAZ untuk arus 100A

Kecenderungan bentuk kurva grafik yang sama, kondisi ini bahwa proses perlakuan preheating untuk ketiga variasi preheating sama baik untuk suhu 200,300 maupun $400^{\circ} \mathrm{C}$. Untuk nilai rerata kekerasan $198,40 \mathrm{HV}$ saat suhu preheatng $200^{\circ} \mathrm{C}, 200,20 \mathrm{HV}$ untuk suhu $300^{\circ} \mathrm{C}$ dan $201,20 \mathrm{HV}$ untuk suhu $400^{\circ} \mathrm{C}$. Pada kondisi ini untuk arus pengelasan 100amp menghasilkan kekerasan tertinggi rerata $201,20 \mathrm{HV}$ untuk suhu preheating $300^{\circ} \mathrm{C}$ dengan persamaan $\mathrm{Y}=0,0833 \times 3$ $0,6071 \times 2+1,3095 x+200,2$. Dari ke tiga variasi suhu preheating tersebut besar selisih nilai kekerasannya $1 \mathrm{HV}$, kondisi ini menunjukkan bahwa saat pengelasan dengan arus 100 amp besar ukuran butirannya seragam (sama).

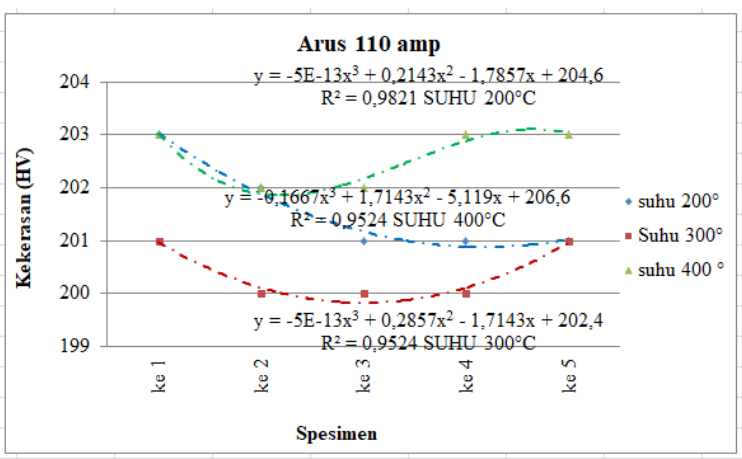

Gambar 5 Perbandingan kekerasan di daerah HAZ untuk arus 110A

Gambar 5 menunjukkan hasil kekerasan saat proses pengelasan menggunakan arus 110 amp yang hasilnya berbeda dari ke tiga variasi preheatng, di mana kecenderungan saat preheating suhu $200^{\circ} \mathrm{C}$ dibandingkan dengan suhu $300^{\circ} \mathrm{C}$ berbeda dan juga terhadap $400^{\circ} \mathrm{C}$. Pada pengelasan menggunakan arus $110 \mathrm{amp}$ untuk ke tiga kondisi preheating ini kekerasan rerata tertingginya $202,60 \mathrm{HV}$ dengan tingkat kepercayaan $95 \%$ dan peramaannnya adalah $Y=-5 E-13 x^{3}+0,2143 x^{2}-1,7857 x+204,6$. Kondisi ini menunjukkan bahwa proses pertumbuhan butir logam bervariasi, di mana saat terjadi kenaikkan nilai kekerasan maka pada logam di HAZ terjadi proses substitusi atau interssi yang banyak. Peningkatan nilai kekerasan tersebut dapat terjadi akibat saat input panas tinggi butiran logam mengembang secara maksimum, pada saat ini unsur dengan ukuran butiran yang kebuh kecil mengisi kekosongannya sehingga menjadi padat, Nilai kekerasan saat pengelasan dengan arus 110 amp dengan suhu preheating $200^{\circ} \mathrm{C}$ $201,60 \mathrm{HV}$, untuk suhu $300^{\circ} \mathrm{C}$ sebesar $200,4 \mathrm{HV}$ dan $202,6 \mathrm{HV}$ untuk suhu $400^{\circ} \mathrm{C}$. Dibandingkan dengan arus 100 
amp terjadi kenaikkan $3,2 \mathrm{HV}$ untuk suhu preheating $200^{\circ} \mathrm{C}$. Untuk suhu preheating $300^{\circ} \mathrm{C}$ naik $0,20 \mathrm{HV}$ dan $\mathrm{k}$ suhu $400^{\circ} \mathrm{C}$ naik $1,40 \mathrm{HV}$, artinya dalam kondisi ini untuk pengelasan menggunakan arus 100 amp terjadi kenaikkan kekerasan maksimum 3,2HV.

Gambar 6 menunjukkan hasil pengelasan SMAW saat menggunakan arus 120amp dengan variasi preheating 200, 300 dan $400^{\circ} \mathrm{C}$ yang menghasilkan kekerasan rerata $205,40 \mathrm{HV}$ saat suhu preheating $200^{\circ} \mathrm{C}$, untuk suhu $300^{\circ} \mathrm{C}$ nilainya $210,20 \mathrm{HV}$ dan untuk suhu $400^{\circ} \mathrm{C}$ nilainya $212^{\circ} \mathrm{C}$. Dibandingkan saat preheating suhu $200^{\circ} \mathrm{C}$ terhadap suhu 300 dengan arus pengelasan yang sama yaitu 120 amp kekerasannya naik 4,80HV dan terhadap preheating suhu $400^{\circ} \mathrm{C}$ naik $6,60 \mathrm{HV}$. Pada kondisi pengelasan $120 \mathrm{amp}$ menghasilkan kekerasan maksimum rerata terbesar $212 \mathrm{HV}$, jadi untuk ke tiga arus pengelasan yaitu 100, 110 dan $120 \mathrm{amp}$ pada daerah HAX kekerasan tertinggi rerata $212,29 \mathrm{~V}$ Persamaannya adalah $Y=0,0833 x^{3}-0,5357 x^{2}+0,381 x+21$. Berdasarkan tingkat kepercayaan 5\% untuk kondisi arus 120amp ini tidak dapat diterima (ditolak) sebab berdasaekan nilai $\mathrm{R}^{2}$ di atas $5 \%$.

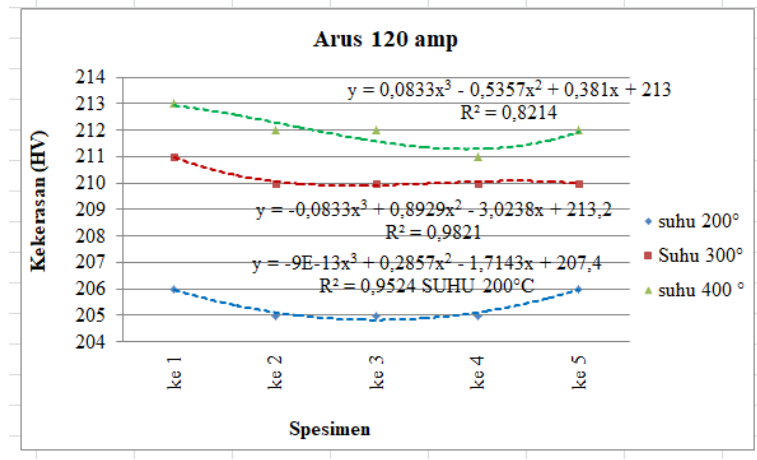

Gambar 6 Perbandingan kekerasan di daerah HAZ untuk arus 120A

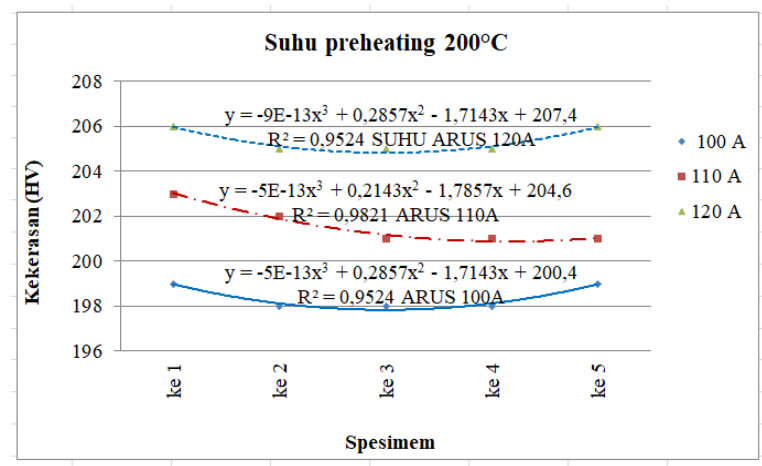

Gambar 7 Perbandingan kekerasan di daerah HAZ untuk suhu preheating $200^{\circ} \mathrm{C}$

Gambar 7 menunjukkan grafik perbandingan nilai kekerasan saat specimen mengalami preheating dengan suhu $200^{\circ} \mathrm{C}$ dengan arus pengelasan yang bervariasi yaitu 100.110 dan 120 amp. Berdasarkan gambar tersebut maka nilai kekerasan tertinggi reratanya saat arus 100 amp 198,40HV dengan tingkat kepercayaan $95 \%$ persamaannya adalah $\mathrm{y}=$ $9 \mathrm{E}-13 \mathrm{x}^{3}+0,2857 \mathrm{x}^{2}-1,7143 \mathrm{x}+207,4$

Untuk arus 110 amp dengan tingakat kepercayaan 95\% persamaannya $y=-5 E-13 x^{3}+0,2143 x^{2}-1,7857 x+204,6$ dan untuk arus 120 amp persamaannya $y=-5 E-13 x^{3}+0,2857 x^{2}$ $1,7143 x+200,4$. Besranya [erubahan kekerasan untuk preheating dengan suhu $200^{\circ} \mathrm{C}$ antara arus 100 terhadap 110amp sebesar 3,2HV dan terhadap arus 120amp sebesar 7HV. Gambar 8 menunjukkan grafik perbandingan nilai kekerasan saat specimen mengalami preheating dengan suhu $300^{\circ} \mathrm{C}$ dengan arus 100.110 dan 120 amp. Berdasarkan gambar tersebut maka nilai kekerasan tertinggi reratanya di daerah HAZ saat arus $100 \mathrm{amp} 200 \mathrm{HV}$ dengan tingkat kepercayaan $95 \%$ persamaannya adalah $\mathrm{y}=-0,0833 \mathrm{x}^{3}+$ $0,8929 x^{2}-3,0238 x+203,2$ Untuk arus 110 amp dengan tingakat kepercayaan $95 \%$ persamaannya $\mathrm{y}=-5 \mathrm{E}-13 \mathrm{x}^{3}+$ $0,2857 \mathrm{x}^{2}-1,7143 \mathrm{x}+200,4$ dan untuk arus $120 \mathrm{amp}$ persamaannya $y=-0,0833 x^{3}+0,8929 x^{2}-3,0238 x+213,2$ Besar perubahan kekerasan untuk preheating dengan suhu $200^{\circ} \mathrm{C}$ antara arus 100 terhadap $110 \mathrm{amp}$ sebesar $0,2 \mathrm{HV}$ dan terhadap arus $120 \mathrm{amp}$ sebesar $10 \mathrm{HV}$.

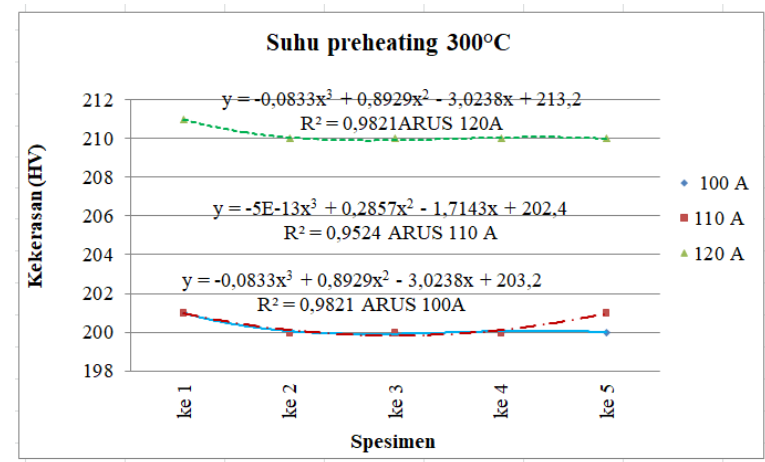

Gambar 8 Perbandingan kekerasan di daerah HAZ untuk suhu pre heating $300^{\circ} \mathrm{C}$

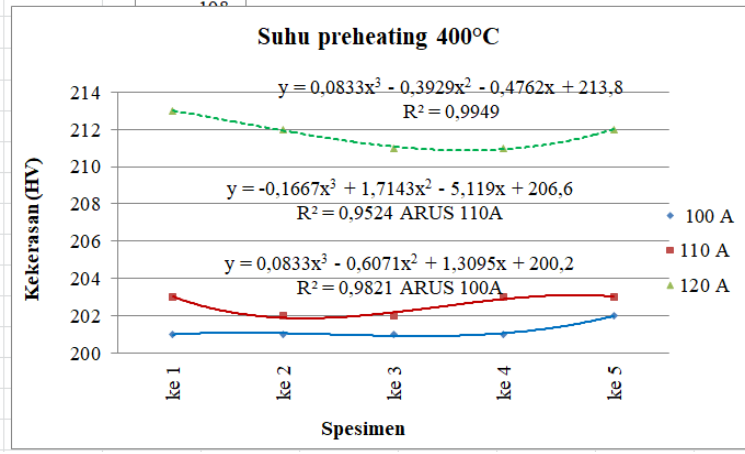

Gambar 9 Perbandingan kekerasan di daerah HAZ untuk suhu pre heating $400^{\circ} \mathrm{C}$

Gambar 9 menunjukkan grafik perbandingan nilai kekerasan saat specimen mengalami preheating dengan suhu $400^{\circ} \mathrm{C}$ dengan arus pengelasan yang bervariasi yaitu 100. 110 dan 120 amp. Berdasarkan gambar tersebut maka nilai kekerasan tertinggi reratanya saat arus $100 \mathrm{amp} 201,20 \mathrm{HV}$ dengan tingkat kepercayaan $95 \%$ persamaannya adalah $\mathrm{y}=$ $y=0,0833 x^{3}-0,6071 x^{2}+1,3095 x+200,2$ Untuk arus 110 amp dengan tingakat kepercayaan $95 \%$ persamaannya $\mathrm{y}=$ $0,1667 x^{3}+1,7143 x^{2}-5,119 x+206,6$ dan untuk arus $120 a m p$ persamaannya $y=0,0833 x^{3}-0,6071 x^{2}+1,3095 x+200,2$. Besranya [erubahan kekerasan untuk preheating dengan suhu $200^{\circ} \mathrm{C}$ antara arus 100 terhadap 110amp sebesar 1,4HV dan terhadap arus $120 \mathrm{amp}$ sebesar 10,6 HV 


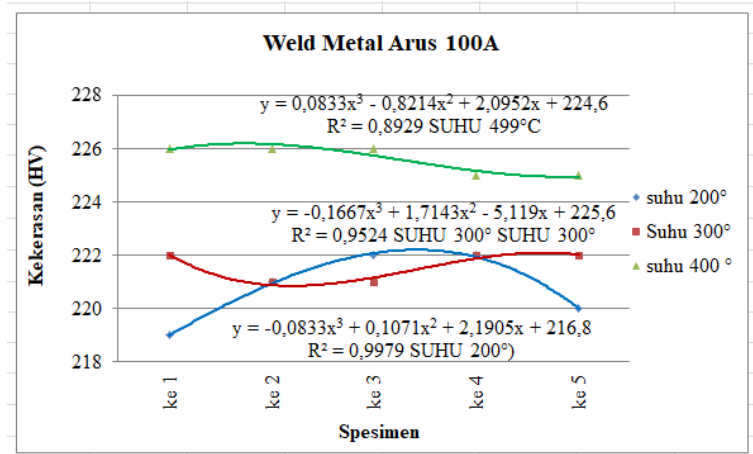

Gambar 10 Perbandingan kekerasan di weld metal untuk suhu arus100 amp

Gambar 10 adalah perbandingan kekerasan hasil pengelasan dengan arus 100amp variasi preheatin, di mana bentuk kurva grafik tidak sama hasilnya, untuk setiap suhu preheating baik untuk suhu 200,300 an $400^{\circ} \mathrm{C}$. Nilai rerata kekerasan dari lima kali pengujian dengan lima specimen menghasilkan kekerasan $220,800 \mathrm{HV}$ saat suhu preheatng $200^{\circ} \mathrm{C}$ dengan persamaan $\mathrm{y}=-0,0833 \mathrm{x}^{3}+0,1071 \mathrm{x}^{2}+2,1905 \mathrm{x}$ $+216,8$, sedang untuk preheating $300^{\circ} \mathrm{C}$ menghasilkan kekerasan 221,60HV dengan persamaan $\mathrm{y}=-0,1667 \mathrm{x}^{3}+$ $1,7143 \mathrm{x}^{2}-5,119 \mathrm{x}+225,6$ serta untuk preheating untuk suhu $400^{\circ} \mathrm{C}$ nilainya $225,60 \mathrm{HV}$ dengan persamaan $\mathrm{y}=-0,0833 \mathrm{x}^{3}$ $+0,1071 x^{2}+2,1905 x+216,8$. Pada kondisi ini untuk arus pengelasan 100amp selisih nilai kekerasannya $1 \mathrm{HV}$, kondisi ini menunjukkan bahwa saat pengelasan dengan arus 100 amp besar ukuran butirannya seragam (sama).

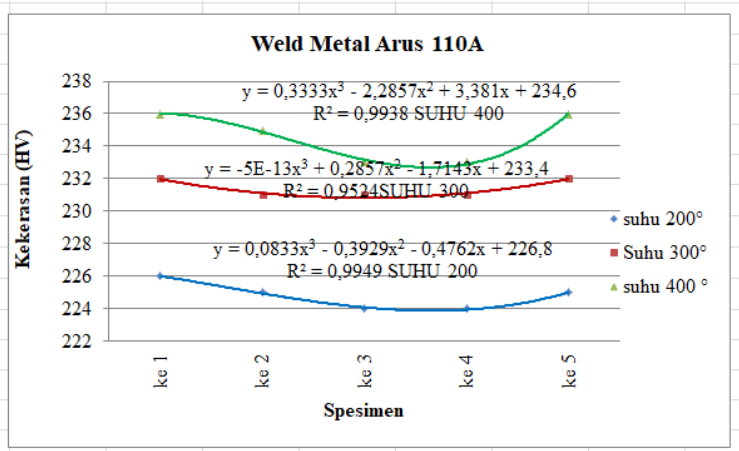

Gambar 11 Perbandingan kekerasan di weld metal untuk suhu arus110 amp

Gambar 11 adalah perbandingan kekerasan hasil pengelasan dengan arus 110amp variasi preheating, di mana bentuk kurva grafik sama model kecenderungannya, untuk setiap suhu preheating baik untuk suhu 200,300 an $400^{\circ} \mathrm{C}$. Nilai rerata kekerasan $224,800 \mathrm{HV}$ saat suhu preheatng $200^{\circ} \mathrm{C}$ dengan persamaan $\mathrm{y}=0,0833 \mathrm{x}^{3}-0,3929 \mathrm{x}^{2}-0,4762 \mathrm{x}+226,8$, untuk preheating $300^{\circ} \mathrm{C}$ menghasilkan kekerasan rerata $231,40 \mathrm{HV}$ dengan persamaan $\mathrm{y}=-5 \mathrm{E}-13 \mathrm{x}^{3}+0,2857 \mathrm{x}^{2}-$ $1,7143 \mathrm{x}+233,4$ serta untuk preheating untuk suhu $400^{\circ} \mathrm{C}$ nilainya $234,60 \mathrm{HV}$ dengan persamaan $\mathrm{y}=0,0833 \mathrm{x}^{3}$ $0,3929 x^{2}-0,4762 x+226,8$ Pada kondisi ini untuk arus pengelasan 110amp. Besarnya perubahan kekerasan antara suhu $300^{\circ} \mathrm{C}$ terhadap $200^{\circ} \mathrm{C} 6,6 \mathrm{HV}$ dan perubahan kekerasan antara suhu $400^{\circ} \mathrm{C}$ terhadap $200^{\circ} \mathrm{C} 9,6 \mathrm{Hv}$

\section{SIMPULAN}

Besar perubahan kekerasan $6,6 \mathrm{HV}$ saat preheating $400^{\circ} \mathrm{C}$ terhadap $200^{\circ} \mathrm{C}$ di daerah $\mathrm{HAZ}$, sedang di weld metal $10,40 \mathrm{HV}$ Yang terjadi saat preheating $400^{\circ} \mathrm{C}$

\section{DAFTAR RUJUKaN}

[1] American Welding Society, 1981, Welding Handbook, 1st Volume, Fundamental of Welding. Miami Florida

[2] Achmad Nurul Qomari, Solichin, Prihanto Tri Hutomo. 2015. "Pengaruh Pola Gerakan Elektrode dan Posisi Pengelasan Terhadap Kekerasan Hasil Las Pada Baja ST 60" .JURNAL TEKNIK MESIN, TAHUN 23, NO. 2, OKTOBER 2015

[3] Hermawan Widi Laksono dan Sugiyanto. 2014. Analisa Hasil Pengelasan Gesek Pada Sambunga Sama Jenis Baja ST 60, Sama jenis AISI 201, dan Beda Jenis Plat Baja ST 60 dengan AISI 201. Jurnal Teknik Mesin S-1, Vol. 2, No. 1, Tahun 2014 Online: http://http://ejournals1.undip.ac.id/index.php/jtm.

[4] Ma'ruf. 2017. Pengaruh Arus Terhadap Kekerasan Hasil Pengelasan Baja ST 60 Menggunakan Pengelasan SMAW. INFO TEKNIK Volume 14 No. 2 Desember 2013 (211-218).

[5] Siswanto Rudi, 2012. Pengaruh Gerakan Elektroda Terhadap Kedalaman Penetrasi dan Panjang Hasil Pengelasan Menggunakan Las Busur Listrik (SMAW). Media SainS, ISSN 2085-3548, Volume 4 Nomor 2, Oktober 2012, 146-153

[6] Wiryosumarto, H.\& Okumura, T., 2008, Teknologi Pengelasan Logam, PT.Pradnya Paramita,Jakarta. 